\title{
Factors affecting successful strategy implementation in the Water Sector in Kenya
}

\author{
${ }^{1}$ Rose Murugi Mbaka, ${ }^{2}$ Dr. Fred Mugambi \\ ${ }^{1,2}$ Jomo Kenyatta University of Agriculture \& Technology, Kenya P.o. Box 81310 - 80100 Mombasa
}

\begin{abstract}
Public sector organizations have best strategies but results of all organizations are not rewarding in accordance to long term objectives. Developing and having strategy alone is not enough. Implementation of a strategy is more important than formulation. Even an effectively developed strategy that reflects the hard choices an organization must make is worthless if it is not implemented. Today many public sector enterprises have failed to implement well thought out strategies. Well formulated strategies only produce superior performance for the firm when they are successfully implemented. Although numerous studies acknowledge that strategies frequently fail not because of inadequate strategy formulation, but because of insufficient implementation. This study sought to review the factors that affect strategy implementation in the Water Sector in Kenya. The study adopted a desk study where secondary data was analyzed to explore the factors that affect the strategy implementation. After reviewing the literature and experts opinion, the studied identified various factor which affects strategy implementation. These were strategy formulation process, relationship among different units/departments and different strategy levels, executors, communication, implementing tactics, consensus, commitment, organization structure, employees and inadequate resources among others. Some of the recommendations that have been recommended which if implemented would ensure successful implementation of strategies are involving the employees during the strategy implementation process, engaging employees through frequent updates, providing adequate resources, aligning of organization structure with the new strategy, proper structures, clear and well developed strategies, motivation, support by top level management, technological infrastructure among others.
\end{abstract}

Keywords: Strategy implementation; Strategy; Water sector; factor analysis

\section{Introduction}

Although formulating a consistent strategy is a difficult task for any management team, making that strategy work - implementing it throughout the organization - is even more difficult (Hrebiniak, 2006). A myriad of factors can potentially affect the process by which strategic plans are turned into organizational action. Unlike strategy formulation, strategy implementation is often seen as something of a craft, rather than a science and its research history has previously been described as fragmented and eclectic (Noble 1999b). It is thus not surprising that, after a comprehensive strategy or single strategic decision has been formulated, significant difficulties usually arise during the subsequent implementation process.

The best formulated strategies may fail to produce superior performance for the firm if they are not successfully implemented, as Noble (1999b) notes. Results from several surveys have confirmed this view. An Economist survey found that a discouraging 57 percent of firms have unsuccessfully at executing strategic initiatives over the past three years, according to a survey of 276 senior operating executives in 2004 (Allio, 2005). According to the white paper of Strategy Implementation of Chinese Corporations in 2006, strategy implementation has become "the most significant management challenge which all kinds of corporations face at the moment. It is thus obvious that strategy implementation is a key challenge for today's organizations. There are many factors that affect the success of strategy implementation.

\subsection{Strategy implementation in water sector}

The Government in its effort to improve service delivery to the public introduced performance based contracts for the top management where they are required to prepare strategies which are cascaded down to the junior staff. The renewal of their contracts is based on the performance management system and as such managers are given tasks with pre-determined successes. Their main role is to strategize how best these targeted results are to be accomplished. The task of formulating strategy entails taking into account all of the relevant aspects of the organization's internal and external environment and coming up with a detailed action plan for achieving the targeted short-run and long term goals.

The transforming and transformed countries have since the1980s embraced reforms that focused on the management of the public sectors which resulted to the public sector being put under pressure to adopt private sector orientations (Economic for Africa Report, 2003). 
At independence, many challenges confronted this sector. Scarcity of resources for development was one of the many challenges facing this sector. The government also was in a hurry to ensure that resources which were available were channeled through the hands of Kenyans. Immediately after independence the colonial masters were still holding resources in their hands, but Kenyans at the same time had the impression that now the resources should be freely available in their hands. Accordingly the first policy after independence - the Sessional Paper No. 10 of (1965), centered on African Socialism and its applicability to planning in Kenya. It mentioned the eradication of the three key economic areas i.e. illiteracy, diseases and poverty.

The main objective of Ministry of Water and Irrigation in Kenya was is to achieve positive development by means of policy instruments that are adapted to the current challenges and thus differ from the previous approaches. Today we still talk of the same important issues which ought to have been dealt with longtime ago. The failure of these policies led to the failures of their implementations. The Government was perceived to be the main player to manage water resources, thereby assuming the responsibility of both financing and management of the services. Strategy implementation under such circumstances was not possible because of too much bureaucracy. Early 1990's the Government promised that water would be available to everybody by the year 2000. The year 2000 came and passed, there was no water in every household. Thereafter the process to develop a new water policy started in 1997. People slowly realized that they needed to change our thinking. The Ministry also realized that it had failed in providing water services since the targets which had been set over a long period were never met.

\subsection{Water Sector reforms in Kenya}

Finally the need to reform the water sector was voiced by the Kenyan population throughout the country. By 1999 the National Water Policy Paper was finalized. This policy marked a major shift in the distribution roles. The role of the Government changed from direct service provision to regulatory and enabling functions. The policy indicated several key issues for achieving integrated water resources management and development. In the year 2002 this national policy paper was presented to parliament for debate and adoption. This marked the birth of Water Act 2002.

The Water Act 2002 created several institutions with specific roles. These were the water boards, Water Service Regulatory Board (WASREB), Water Trust Fund (WSTF), Water Resource Management Authority (WARMA) and Water Appeal Board (WAB). Water Resource Management Authority was to manage and protect the water resources. The Water Services Boards were to manage water service assets and the decentralized distribution system through Water Service providers (WSPS). The overall supervision of water services was to be carried by Water Services Regulatory Board (WSRB). Water Appeal Board was to manage dispute resolutions among the several players in the water sector. Water Act 2002 also created Area catchments Advisory committees being selected and Water Users Associations. In all these new arrangements, the Ministry of Water and Irrigation maintained the overall responsibility of policy formulation at the national level. (Water Act 2002).

Fig 1.1: Institutions in the Water Sector: (Water Act 2002)

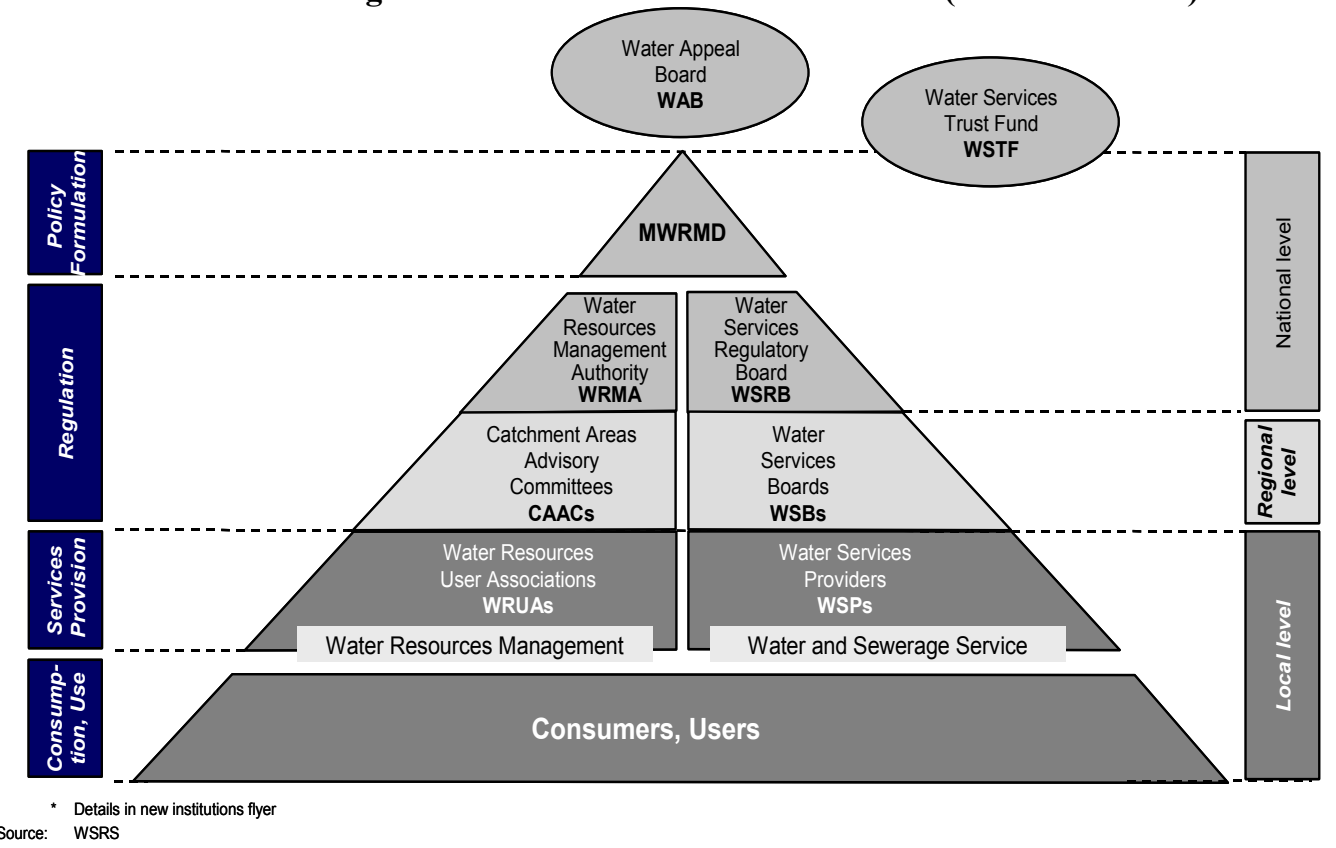




\section{Purpose of the study}

The purpose of the study was to explore the factors which affect the strategy implementation in the water sector in Kenya and thereafter offer recommendations on the way forward.

\section{Methodology}

In order to identify the factors that affect strategy implementation in the water sector, the study employed desktop research by reviewing existing literature, government reports, articles, websites, journals and books.

\section{Strategy Implementation}

Strategy implementation is the amplification and understanding of a new strategy within an organization (Mintzberg, 1994). Such an explanation involves the development of new structures, processes and other organizational alignments (Galbraith \&Kazanjian, 1986).

Implementation is a key stage of the strategy process, but one which has been relatively neglected (Noble, 1999, Dobni and Luffman 2003, Bantel and Osborn, 2001). Despite this it is generally perceived as a highly significant determinant of performance. As Noble (1999:119) states, "well formulated strategies only produce superior performance for the firm when they are successfully implemented". There seems to be widespread agreement in the literature regarding the nature of strategic planning, which includes strategy implementation. It includes presentations of various models showing the organizational characteristics suggested as significant factors for effective strategy implementation (Guffy, 1992). It is also portrayed as a lively process by which companies identify future opportunities (Reid, 1989). Additionally, the existence of a strategy is an essential condition or precondition for strategy implementation. Implementation is focused by nature and by definition. It cannot be directionless. It is a process defined by its purpose - in this case, the realization of a strategy. Thus, to implement a strategy, there must be a strategy. The strategy may be more or less well-formed, more or less in the process of formation, or even emergent (Mintzberg, 1987). Unless it is suitably formed to represent a direction or goal, there is nothing to implement; and organizational members will be unable to work towards its realization. As a result, strategic intentions are inextricably linked with, and enable the existence of, strategy implementation. As well, organizations that focus their energy on harvesting the fluid relationship between strategy and implementation will create satisfied customers, employees, and greater profits (Beaudan, 2001).

\subsection{Factors leading to successful strategy implementation}

According to Peng and Littleljohn (2001) effective communication is a key requirement for effective strategy communication. Organization communication plays an important role in training, knowledge dissemination and learning during the process of strategy implementation. Therefore effective communication should clearly explain the new responsibilities, duties and tasks which will be done by targeted employees. The management should ensure every staff member understands the strategic vision, the strategic themes and what their role will be in delivering the strategic vision. It is important that all employees are aware of expectations. How are they expected to change? What and how are they expected to deliver? Each individual must understand their functions within the strategy, the expected outcomes and how they will be measured.

Rapert and Wren (1998) found out that organizations where employees have easy access to management throughout open and supportive communication climates tend to outperform those with more restrictive communication environments.

Nutt (1986) suggested that the tactics used in leadership plays an important role in overcoming obstructions from the lower levels that sometimes may appear in the implementation strategies. Nutt (1987) noted that strategic decisions formulated by the top managers of a firm may be administratively imposed on lower-level managers and non managers while inadequately considering the resulting functional level perceptions. The implementation of strategies therefore, may not be successful if the lower level managers and the non-management employees are not adequately informed on issues concerning the implementation of strategies, moreover, where the information passes through several management levels in an organization may lead to lack of consensus concerning the information hence creation of a barrier that hinders the success of implementing a strategy (Noble, 1999b).

Chimanzi and Morgan's (2005) study indicated that firms which focus their attention to involvement of all employees significantly realize higher percentages of strategy implementation. Therefore Chimanzi and Morgan's (2005) proposed that organization should involve all the employees for the success of the strategy.

Allocating adequate funds and managing the budgets to deliver the company's strategic initiatives is fundamental for the success of any strategy. It is recommended that the strategic initiatives be allocated specific budget alongside capital and operating budgets. This protects strategic expenditure from being reallocated to short term requirements whilst subjecting strategic initiatives to a rigorous review. 
According to Heide \& Gronhaug \& Johannessen's (2002) organization structure plays an important role in the strategy implementation. Drazin and Howard (1984) see a proper strategy -structure alignment as a necessary precursor to the successful implementation of new business strategies. The structure should be changed to allow room for implementation strategy. A transformational strategy may require a transformation structure. Does the structure of the organization allow strategy to cascade across and down the organization in way that meaningfully and efficiently delivers the strategy?

The organization must have strategy control systems to measure and track the execution of the strategy. They must be able to monitor the strategy implementation so that if there are any deviations corrective measures can be taken to correct them. The criteria of the success of strategic decisions are not specific and clear.

Commitment by decision makers in the organization can lead to successful implementation of strategy. Shared understanding without commitment may result in "counter effort" and negatively affect performance (Wooldridge \& Floyd, 1989, cited in Rapert, Lynch and Suter 1996).Shared understanding of middle management and those at the operational level to the top management is of critical importance to effective implementation (Rapert \&Velliquette\& Garretson, 2002). Strategy implementation effort may fail if the strategy does not enjoy support and commitment by the majority of employees and middle management. This may be the case if they were not consulted during the development phase (Heracleous, 2000). When decision makers do not have interest and commitment to the implementation of the strategies, the strategies are bound to fail.

The technological Infrastructure can give an organization valuable assistance in implementing new policies, procedures and initiatives. Utilize technology to enhance and maintain communication and accountability for all relevant managers and operational employees throughout the change process, and to keep track of implementation and performance goals and their achievement.

Human Resource capabilities (executors) play a very critical role in strategy implementation. Executors are comprised of top management, middle management, lower management. Effectiveness of strategy implementation is, at least in part, affected by the quality of people involved in the process (Govindarajan, 1989). Here, quality refers to skills, attitudes, capabilities, experiences and other characteristics of people required by a specific task or position (Peng \&Litteljohn 2001). The Human Resource capabilities or the people working in an organization are the key to achieve effective implementation of the strategy. Knowledgeable, dependable and versatile employees have the ability to overcome the obstacles to change and can meet performance goals even when other resources are scarce. If all other elements are present, but the workforce does not meet these criteria, then achieving the implementation of the strategy may be nearly impossible. Viseras, Baines and Sweeney (2005) in their research findings indicated that strategy implementation success depends crucially on the human or people side of project management and less on organization and systems related factors.

Incentive Systems/motivation system in an organization can greatly affect the implementation of strategy. An organization should consider altering existing incentive systems to coincide with the new strategic objectives. As an example, if the existing incentive system rewards employees on the basis of tenure, but the new strategic calls for a 50 percent increase in service plan sales to reposition your company as a service provider, then consider altering the system to reward employees or teams with high monthly service plan sales numbers.

Nielsen (1983) contends that firms must achieve consensus both within and outside the organization in order to successfully implement business strategies (Nobble 1999b). The agreement among top, middle and operating level managers will result to successful implementation of the strategy. If there is no understanding among them it may create obstacles to successful strategy implementation.

It is clear that a poor or vague strategy formulation process can limit implementation efforts dramatically. Good execution cannot overcome the shortcomings of a bad strategy or poor strategic planning effort (Hrebiniak ,2006).

Alexander (1985) believes that the need to start with a formulated strategy that involves a good idea or concept is mentioned most often in helping promote successful implementation. As Allio, 2005 notes, good implementation naturally starts with good strategic input: the soup is only as good as the ingredients (Allio, 2005).

Relationship among different units/departments and different strategy levels. Several studies treat institutional relationships among different units/departments and different strategy levels as a significant factor that affects the outcome of strategy implementation (Walker \& Ruekert, 1987; Gupta, 1987; Slater \& Oslon, 2001; Chimanzi, 2004; Chimanzi\& Morgan 2005). Walker \& Ruekert 1987 stipulates that corporate-business unit relationships, inter-functional structures and process marketing policies and process may all significantly influence business strategy implementation. Chimanzi (2004) suggests that the cross unit working relationships 
have a key role to play in the successful implementation of decisions. Implementation effectiveness is affected negatively by conflict and positively by communication.

The McKinsey $7 \mathrm{~S}$ model of strategy implementation summarizes them by stating that managers need to take account seven factors to be sure of successful implementation of a strategy. These are the 7 s namely strategy, structure, systems, style, staff, superordinate goals and skills. A strategy is a set of actions that you start with and must maintain. Structure is the way people and tasks/work are organized, systems are the processes and information flows that link the organization together, style is the way managers behave, staff is the way an organization develops managers (i.e both current and future), superordinate goals are the Longerterm vision, and all that values stuff, that shapes the destiny of the organization while skills are the dominant attributes or capabilities that exist in the organization.

All these are all interdependent, so if one fails to pay proper attention to one of them, it can bring the others crashing down around you. The relative importance of each factor will vary over time. The Framework is useful way of checking that one has covered all the bases.

\section{Mckinsey 7s model}

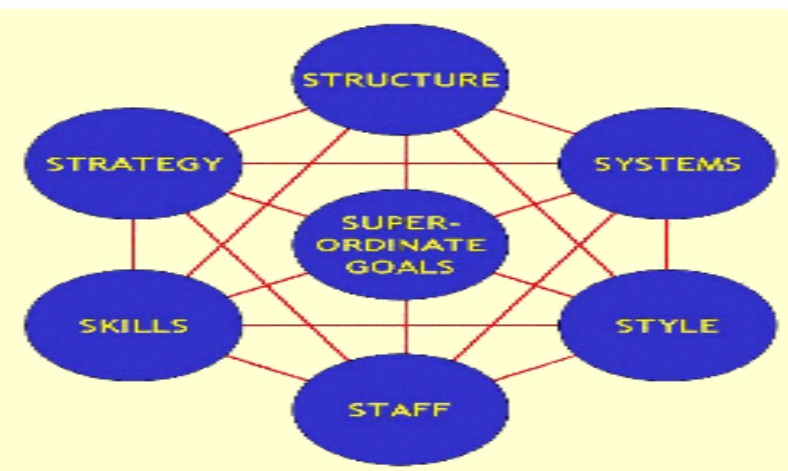

Source:Waterman et al (1980)

\subsection{Failure of Strategic plan Implementation}

Strategy implementation is more important for the organization than the strategy formulation because if the strategy is not successfully implemented by the staff and management, its cost and damages grow more than the failure of strategy formulation. The main reasons of failure of the strategy implementation are as follows.

Feurer at al (1995) identified lack of communication among the strategy makers and staff and management of the organization. This can either be lack of communication or poor communication.

Schaap (2006) in his research findings in the Casino Industry found out that failure to communicate the vision and strategic objectives to employee's means that the strategy makers are not giving information for everybody to understand what they are supposed to do with it. New objectives are outlined but not communicated throughout the organization as to how the new objectives should look and what steps are supposed to be taken. Poor communication among team members is responsible for poor decisions in implementations. Expectations and opinions are not shared openly, thoroughly and effective.

Jooste and Fourie (2009) argued that there are many organizations which have various strategies but due to lack of commitments of the policy makers and lack of strategic leadership these strategies do not generate the fruitful results. The other reasons behind the failure of strategy are lack of interest and efficient leadership to implement.

Mapeter et al (2012) stated that the reasons which cause failure of the strategies and despite having the best strategies, they could not bring forth results in Zimbabwe was only on account of negative leadership behavior which shows the strategy executive people were not liable, they were less committed to the strategy. Lack of creative strategic vision in the organization they could not motivate and boot up morals of staff to obtain the determined objectives, communication among the middle level management and high level management in organization remained very low.

Schaap (2006) stated that top management and leadership behaviour affect the success of implementation of the strategy. Manager's inadequate understanding of company strategies and future outlook, as well as inadequate attention and support of managers and other influencing people in the organization towards the implementing of business strategies hinder the successful implementation of strategies.

Kalali et al 2011 after conducting a study in the Iranian Health Sector came up with sixteen factors as outlined in the table below:- 
Table 5.1: Factor Detail

\begin{tabular}{|l|l|}
\hline Content dimension & Content dimensions include the ingredients involved in the strategy formulation \\
\hline Contextual dimensions & $\begin{array}{l}\text { Contextual dimensions include the internal and external environmental for the strategy } \\
\text { implementation in water sector organizations }\end{array}$ \\
\hline Operational dimensions & $\begin{array}{l}\text { Operational dimensions refer to the problems which happen in the operational level during the } \\
\text { strategy implementation }\end{array}$ \\
\hline Structural dimensions & $\begin{array}{l}\text { Structural dimensions point out the organizational structure and power and responsibilities } \\
\text { distributions }\end{array}$ \\
\hline
\end{tabular}

Source: AbdulwahidSial, 2013

Table 5.2: Details of the factors dimensions which cause the failure of strategy implementation

\begin{tabular}{|c|c|}
\hline 1 Resource limitation & $\begin{array}{l}\text { Budget, technology, tools and human resources are inadequate for strategic decision } \\
\text { implementation }\end{array}$ \\
\hline 2 Background & It is culture of public sector organization to always fail in implementation \\
\hline $\begin{array}{l}3 \text { Lack of integration (poor } \\
\text { communication) }\end{array}$ & All most departments of the public sector organization are not integrated to each other \\
\hline 4 Conflicting goals and priorities & Goals and priorities are influenced by personal interest \\
\hline 5 Environmental uncertainty & Unpredicted problems happen due to change in government, political, social and leadership \\
\hline 6 Non-convergence & Co-ordination of core player activities is poor and inefficient \\
\hline 8 Lack of team management & Instruction and involvement of team leader is insufficient \\
\hline $\begin{array}{ll}\text { 9.Ineffective } & \text { operational } \\
\text { arrangement } & \end{array}$ & Responsibilities of people are not assigned and defined in proper manner \\
\hline 10. Lack of support of top level & $\begin{array}{l}\text { Insufficient support of Director and head of Department in implementation of strategic plan } \\
\text { implementation }\end{array}$ \\
\hline $\begin{array}{l}\text { 14. Lack of commitment of } \\
\text { decision makers }\end{array}$ & Decision makers do not have interest and commitment to implementation of the strategy \\
\hline 15. Ambiguous strategy & The decided strategy is not understandable and well-defined \\
\hline $\begin{array}{l}16 . \quad \text { Non convergence of } \\
\text { organizational varied aspects to } \\
\text { considered strategy }\end{array}$ & $\begin{array}{l}\text { There is no arrangement between processes, work systems and other dimensions of the } \\
\text { organization with the organizational strategy. }\end{array}$ \\
\hline
\end{tabular}

Source: AbdulwahidSial, 2013

\section{Discussions}

After analyzing all the previous literature available, the research has agreed on the following factors which are used repeatedly and frequently in almost all researches. These factors equally affect successful strategy implementation in the Water Sector in Kenya.

The employees in the public sector lack the right skills, altitudes and capabilities to drive through the implementation process.

There is lack of communication between the strategy formulators and the employees. Employees are not well informed about the strategies and the various tasks they are supposed to perform. In certain cases, the employees are not even aware of the vision and the mission of their organizations.

Resources are not adequate to see the full implementation of the strategies in the water sector which led to strategies being implemented half way, which is very costly to the organization.

Lack of proper information systems is a major obstacle in implementing strategy implementation in the water sector. The water sector being a Government managed sector still lags behind in terms of technological infrastructure and this has greatly affected the implementation of the strategies.

Wrangles between the management/lack of support from top level management in the organizations are another impediment to the strategy implementation. Instead of Managers concentrating on how they could implement the strategies they are caught up in wrangles and hence pulling in different directions which has made it difficult to implement strategies though well crafted.

The current organization structure prevents the sector from implementing the strategy since the structures have not been aligned with the new strategies. A transformational strategy requires a transformation structure which is lacking currently

There is poor relationship among different units/departments in the organizations. This has brought about organizational conflicts that have resulted in ineffectiveness in implementing the strategies. The poor relationship among the different departments has brought about conflicts among themselves. This has greatly affected the strategy implementation in the water sector. 
There is no commitment by decision makers and as such there is no shared understanding among them resulting in situations where they pull in different directions hence resulting to failure of strategy implementation.

There is no consensus agreement among top, middle and operating level managers which has led to failure of the strategy implementation.

Lack of involvement of employees during the strategy formulation process is also a great impediment to the successful implementation of strategies. Strategies are often formulated in the Boardrooms with a few top level managements and consultants. Employees were not involved during the formulation process and hence were not willing to support the process of implementation.

There is lack of strategy control systems in the organization. The water sector has not put any mechanism in place to control and manage execution progress and it is not easy to determine whether the strategic decision has been achieved or not or whether they are any deviations which could be corrected.

The staff incentives not aligned with strategy. The employee's incentives in the water sector have not been aligned with the new strategy. Motivation of staff is very critical as will affect employee performances.

\section{Conclusions}

Due to globalization, the competition among public and private organizations has significantly increased and tough time job for managers to maintain the level of organization in market and survive in competition. The sector faces stiff competition from bottled water companies, boreholes and it's no longer a monopoly and therefore a single mistake by management in strategy formulation and implementation can lead to disastrous effects to the organizations.

The results show that the most important reason for the failure of the strategy implementation in the water sector in Kenya is operational plan of the implementation. Operational dimensions include resources limitation, incompetent management and staff, poor planning for execution and lack of integration among the department are the main reasons for failure, followed by structural and contextual dimensions.

\section{Recommendations}

The following are some of the recommendations that if implemented can lead to a successful strategy implementation in the water sector.

The organization should train its employees to equip them with the right skills so that they are to cope up with the new roles of strategy implementation or hire competent employees that have the right skills, altitudes and capabilities to drive through the implementation process.

The management should develop a good communication system to disseminate information to employees. They should be updated on all the strategies that have been developed by the strategy formulators. They need to be well informed about these strategies and the various tasks they are required to perform during the strategy implementation process

The Government should support the water sector though allocation of adequate resources which will see through the implementation process of the strategy.

The organizations should provide technological infrastructure that will give an organization valuable assistance in implementing new policies, procedures and initiatives for the success of the strategy implementation process.

Support of top level management is crucial to strategy implementation. The Directors and heads of Departments should provide sufficient support in implementation of strategies.

The management should develop new organizational structure which is aligned to the new strategy. The management should align its own organizational structure to what the strategy is calling for in order to enhance effectiveness of communication and coordination during the implementation process. This can be done by reducing the structure from tall to flat structures.

The management should ensure that there is healthy interdepartmental relationship among different units/departments for the success implementation of strategy and should be encouraged in the departments. This could be achieved through attending team work activities, workshops and seminars.

The management should also ensure commitment by all decision makers to enable them to achieve same objectives.

The management should ensure that they gain consensus among all the levels of management for the successful implementation of the strategy.

The organizations should involve the employees during the strategy formulation process so that everyone can own it and work for the good of it.

The management should develop strategy control systems so that they are able to monitor the strategy execution and therefore recommend corrective measures and also monitor the success of the strategy execution. The organizational management should align employee performance during implementation phase with the overall reward and compensation system in the organization. 
They should also organize training and educational seminars clarifying the advantages of implementing of strategies explaining to the employees what they stood to benefit when the strategies are successfully implemented.

It is also important to note that implementation is an ongoing process not an annual event and thus it should be updated often to ensure relevance with the competitive environment. Even though the sector is Government oriented, they should also try to change from the old ways of doing business to the modern way where strategies once crafted are implemented.

\section{Further research}

The subject of strategy implementation studies are not only state-owned corporations but also private corporations. However, there have been no studies comparing similarities and differences of strategy implementation among private corporations and state-owned corporations.

\section{References}

[1]. Abdulwahid S., Muhamad K. U, Sehar Z., Arshad M. S. and, Iftekhar K. (2013) why do public Sector organizations fail in Implementation of Strategic Plan In Pakistan, Journal of PublicPolicy and Administration Research, Vol.3, No. I, 2013

[2]. Allio, M.K (2005), 'A Short, Practical Guide to Implementing Strategy' Journal of Business Strategy, 26, 12-21

[3]. Bantel, K.A (1997), Performance in Adolescent, Technology - Based Firms: Product Strategy Implementation and Synergy'. The Journal of High Technology Management Research, 8 243-262

[4]. Beaudan, E. (2001), January/February). The failure of strategy. It's all in the execution. Ivery business, Journal, 65 (3), 64 - 68

[5]. Chimhanzi, J. (2004). The Impact of marketing/HR interactions on marketing strategy implementation, European journal of Marketing, 38, 73-98

[6]. Chimhanzi, J., and Morgan, R. E (2005), 'Explanations from the marketing/human resources dyad for marketing strategy implementation effectiveness in service firms'. Journal of Business Research, 58, 787-796.

[7]. Feurer, R. and Chaharbaghi K., (1995) Strategy Development, Past, Present and Future, Management Decision, Vol. 33, No. 6, Chesbrough, H. (2002)

[8]. Galbraith, J. R. \&Kazanjian, R. K. (1986), Strategy Implementation, Structure Systems and process, St. 12 Paul, MN: West Publishing.

[9]. Government National Water Policy Paper, (1999)

[10]. Government Sessional Paper No. 10 of (1965).African Socialism based on eradication of Illiteracy, disease and poverty

[11]. Govindarajan V. (1989), 'Implementing Competitive Strategies at the Business Unit Level: Implications of Matching Managers to Strategies', Strategic Management Journal, 10, 251- 269

[12]. Guffy, W.R. (1992). The role of organization communication in the implementation of a business unit strategy. Doctoral dissertation, Virginia Polytechnic Institute and State University. VA.

[13]. Heracleous, L. (2000), 'The Role of Strategy Implementation in Organization Development'. Organization Development Journal, $18,75-86$

[14]. Hrebiniak, L.G (2006), 'Obstacles to Effective Strategy Implementation, Organizational Dynamics, 35, 12-31

[15]. Johnson, Scholes, (2008). Exploring Corporate Strategy $8^{\text {th }}$ Edition, Prentice Hall, Financial Times.

[16]. Joostle and Fourie (2009), the role of strategic leadership in effective strategy implementation: perception of South African Strategic leaders, South African Business Review, $13(30,51,68)$

[17]. Kalali S. Anvari M. Asghar A. and Karimany (2011), Why does Strategic plans implementation fail? A study in the health sector of Iran, Vol. 5 (23), pp 9831-9837, 7 October, 2011

[18]. Kaplan, R, S., \& Norton, D. P. (2005), The Office of strategy Management, Harvard Business Review, (83) (10), 72-

[19]. Mintzberg, H. (1978) Patterns in Strategy Formulation .Management Science, Journal of Management. 17-24

[20]. Noble, C.H. (1999).The Eclectic Roots of Strategy Implementation Research. Journal of Business Research, 45,119 134.

[21]. Nutt, P.C. (1986). Tactics of Implementation'. Academy of Management Journal. 29 231-261

[22]. Oslen, M. D., Tse, E. C.-Y \& West, J.J. (1992) Strategic Management in the Hospitality Industry, New York, Van Nostrand Reinhood.

[23]. Oslon, E. M., Slatter, S. F., and Hult, G. T. (2005) 'The importance of structure and process to Strategy Implementation, Business Horizons, 48, 47-54

[24]. Peng, W., and Littlelijohn, D. (2001), 'Organizational Communication and Strategy Implementation - A primary inquiry'.International Journal of Contemporary Hospitality, 13, 360-363.

[25]. Peters, T. and Waterman, R., 'In Search of Excellence', Harper and Row, New York 1982

[26]. Schaap, J. I. (2006). 'Toward strategy implementation Success: An Empirical Study of the Role of Senior-Level Leaders in the Nevada Gamming Industry’. UNLV Gamming Research \& Review Journal, 10, 13-37

[27]. Rapert M. I. Lynch. D., and Suter, T. (1996). 'Enhancing Functional and Organization

[28]. Reid, D.M. (1989). Operationalizing Strategic Planning. Strategic Management Journal, 10,553 - 567.

[29]. Viseras, E. M. Baines,. T., and Sweeney, M. (2005),.Key success factors when implementing strategic manufacturing initiatives'. International Journal of Operations and Production Management, 25, 151-179

[30]. Waldersee, R., and Sheather, S. (1996)., 'The Effects of Strategy Type on Strategy Implementation Actions' Human Relations, 49 $105-122$

[31]. Walker, Jr, O.C., and Ruekert, R. W. (1987).'Marketing's Role in the Implementation of Business Strategies: A Critical Review and Conceptual Framework'. Journal of Marketing 51, 15-33.

[32]. Water Act, (2002) Water Sector Reforms .Ministry of Water and Irrigation, Nairobi, Kenya

[33]. Wooldridge, B., and Floyd, S. W. (1990) 'The Strategy Process, Middle Management Involvement and Organization Performance'. Strategic Management Journal, 11, 231-241

[34]. Yang Li, Sun Guohui, and Martin J. Epper (2008), 'Making Strategy Work: A literature Review on the factors influencing strategy implementation. ICA Working Paper, 2/2008, Institute of Corporate Communication. 